\title{
An (Eco)Toxicity Life Cycle Impact Assessment Framework for Per- And Polyfluoroalkyl Substances
}

Holmquist, Hanna; Fantke, Peter; Cousins, Ian T.; Owsianiak, Mikoaj; Liagkouridis, loannis; Peters, Gregory M.

\section{Published in:}

Environmental Science and Technology

Link to article, DOI:

10.1021/acs.est.9b07774

Publication date:

2020

Document Version

Publisher's PDF, also known as Version of record

Link back to DTU Orbit

Citation (APA):

Holmquist, H., Fantke, P., Cousins, I. T., Owsianiak, M., Liagkouridis, I., \& Peters, G. M. (2020). An (Eco)Toxicity Life Cycle Impact Assessment Framework for Per- And Polyfluoroalkyl Substances. Environmental Science and Technology, 54(10), 6224-6234. https://doi.org/10.1021/acs.est.9b07774

\section{General rights}

Copyright and moral rights for the publications made accessible in the public portal are retained by the authors and/or other copyright owners and it is a condition of accessing publications that users recognise and abide by the legal requirements associated with these rights.

- Users may download and print one copy of any publication from the public portal for the purpose of private study or research.

- You may not further distribute the material or use it for any profit-making activity or commercial gain

- You may freely distribute the URL identifying the publication in the public portal 


\title{
An (Eco)Toxicity Life Cycle Impact Assessment Framework for Per- And Polyfluoroalkyl Substances
}

\author{
Hanna Holmquist,* Peter Fantke, Ian T. Cousins, Mikołaj Owsianiak, Ioannis Liagkouridis, \\ and Gregory M. Peters
}

Cite This: Environ. Sci. Technol. 2020, 54, 6224-6234

Read Online

\section{ACCESS | Lill Metrics \& More | 回 Article Recommendations ｜（） Supporting Information}

ABSTRACT: A framework for characterizing per- and polyfluoroalkyl substances (PFASs) in life cycle impact assessment (LCIA) is proposed. Thousands of PFASs are used worldwide, with special properties imparted by the fluorinated alkyl chain. Our framework makes it possible to characterize a large part of the family of PFASs by introducing transformation fractions that translate emissions of primary emitted PFASs into the highly persistent terminal degradation products: the perfluoroalkyl acids (PFAAs). Using a PFAA-adapted characterization model, human toxicity as well as marine and freshwater aquatic ecotoxicity characterization factors are calculated for three PFAAs, namely perfluorooctanoic acid (PFOA) perfluorohexanoic acid (PFHxA) and perfluorobutanesulfonic acid (PFBS). The model is evaluated to adequately capture long-term fate, where PFAAs are

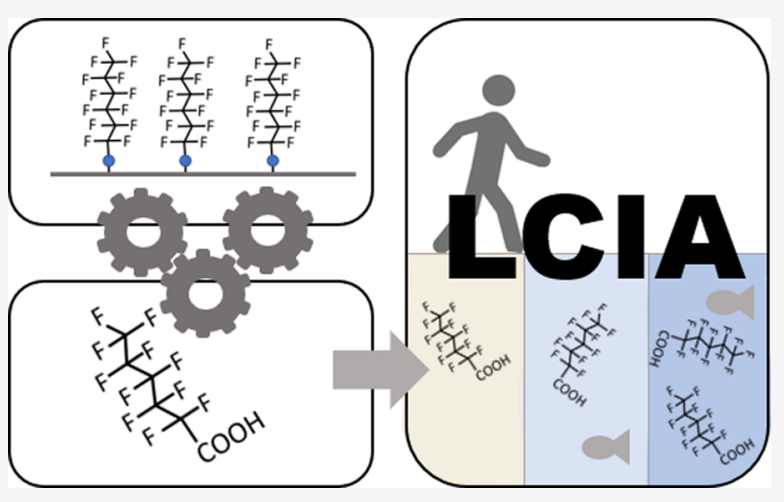
predicted to accumulate in open oceans. The characterization factors of the three PFAAs are ranked among the top 5\% for marine ecotoxicity, when compared to 3104 chemicals in the existing USEtox results databases. Uncertainty analysis indicates potential for equally high ranks for human health impacts. Data availability constitutes an important limitation creating uncertainties. Even so, a life cycle assessment (LCA) case study illustrates practical application of our proposed framework, demonstrating that even low emissions of PFASs can have large effects on LCA results.

\section{INTRODUCTION}

Life cycle assessment (LCA) is an ISO-standardized decisionsupport tool for quantification of potential environmental and human health impacts of goods or services along their entire life cycles. Its four phases include setting of goal and scope, life cycle inventory (LCI) analysis, life cycle impact assessment (LCIA), and interpretation. ${ }^{1}$ The LCI phase requires the generation of a quantitative list of resources used and emissions released by the studied product or service life cycle. In the LCIA phase, these inventory flows are multiplied by substance-specific impact characterization factors (CFs) to estimate aggregated burden indicators. These LCIA indicators should cover all relevant impacts, such as global warming, eutrophication, acidification, and ecotoxicity and toxicity. This broad coverage makes LCA a valuable tool for identification of potential problem shifting in comparative studies of two product or service systems providing the same function, as well as in single system studies for optimization of its environmental performance.

Per- and polyfluoroalkyl substances (PFASs) are widely used both as industrial chemicals and in consumer products. ${ }^{2}$ PFASs provide unique properties in practical applications with their durability and repellency to both oil and water, properties that also impart special fate and exposure properties. ${ }^{3,4}$ Environ- mental degradation of PFASs creates highly persistent end products, usually the perfluoroalkyl or perfluoroalkyl(poly)ether acids (PFAAs). ${ }^{5}$ Continuous emissions of PFASs will lead to increasing exposures of PFAAs either following their direct emission or through the transformation of PFASs to PFAAs, this is because PFAAs may require centuries to achieve steady-state in some environmental media. ${ }^{5-8}$ These emissions and subsequent rising exposures may lead to toxic effects on ecosystems and humans"10 (hereafter "(eco)toxic effects"). Several PFASs have been shown to be toxic and are being banned or restricted, e.g. perfluorooctanesulfonic acid $(\mathrm{PFOS})^{11}$ and perfluorooctanoic acid (PFOA). ${ }^{12,13}$ Concerns have also been raised about possible future adverse (eco)toxic impacts of other PFASs, for example, PFASs with shorter perfluoroalkyl chains than PFOS and PFOA.,

LCIA of products or service systems that contain PFASs requires characterization of the fate, exposure, and effects of

Received: December 20, 2019

Revised: April 14, 2020

Accepted: April 14, 2020

Published: May 4, 2020

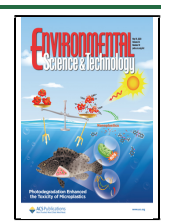


LCA step

LCI
Inventory of all PFAS emissions in the studied

system, including polymeric products and impurities (primary pollutants) procedure

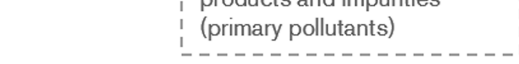

4

Input information
PFAS use in products and emission factors
Transformation

LCIA

Figure 1. Illustration of the workflow of the proposed framework and presteps of the LCIA. The framework covers the black parts of the figure and greyed out parts are described in overview in the Supporting Information and exemplified in the case study.

PFASs with consideration of the unique chemical properties of this substance group. Key considerations for capturing the potential impacts of PFASs in LCIA are the diversity of PFASs (there are more than 4000 PFASs registered in the latest $\mathrm{OECD}^{2}$ list), the high persistence and accumulation potential of the terminal degradation products (often rendering these relatively more important in environmental assessments compared to their related primary pollutants ${ }^{5}$ ) and their amphiphilicity (oleophobic and hydrophobic) and protein binding properties. ${ }^{3,4,14}$ Transformation products are normally not included in LCIA, ${ }^{15}$ but for PFASs, inclusion of PFAA transformation end products is essential due to their environmental persistence and resulting accumulation. Currently an LCA-analyst lacks an appropriate description of the impact pathways for PFASs considering these factors. The few available CFs either do not include several of the PFASs recognized as hazardous, ${ }^{16,17}$ or include these substances without full consideration of the long-term potential impacts resulting from fate and exposure specific to PFASs, due to missing factors for relevant impact categories such as marine ecotoxicity and the disregard of partitioning and bioaccumulation properties specific to PFASs. ${ }^{18,19}$ An (eco)toxicity LCIA framework adapted to PFASs would allow for more robust decision support concerning PFASs and broader scopes in LCA, ${ }^{20-25}$ as potential impacts related to PFASs would be included in results and therefore considered in related decisions supported by the LCA. It could also demonstrate a general approach to the inclusion of chemicals with highly persistent degradation products in LCA.

To address this need for specific considerations related to PFASs in LCIA, the goal of the present paper is to propose an (eco)toxicity LCIA characterization framework for PFASs, which provides a consistent way to include emissions of PFASs and characterize those in terms of potential aquatic ecotoxicity and human toxicity cancer and non-cancer impacts for use in LCA. To achieve this goal, we defined three specific objectives: (i) to define the link between reported emissions of PFASs and one or more related degradation products considered terminal, (ii) to characterize these terminal degradation products in terms of (eco)toxicity impacts, focusing on the use of empirical data but allowing for the use of estimated data wherever empirical data are missing, and (iii) to apply the proposed framework in an illustrative case study of PFASs in textiles.

\section{METHODS}

2.1. Overview of the Proposed Characterization Framework for PFASs. The proposed (eco)toxicity characterization framework for PFASs consists of two parts, providing the input information that aid the LCA-analyst in the steps from LCI to LCIA (Steps A and B illustrated in Figure 1). The input information into Step $A$ is a translation table, which can be used to convert the LCI of quantified primary emissions of PFASs (i.e., the large family of PFASs) into an inventory of terminal degradation product emissions (i.e., the PFAAs). Such a translation table is needed whenever the primary pollutant emission is not a PFAA itself, to arrive at a time integrated LCI. The input information into Step $B$ is an impact characterization model developed for quantifying human toxicity as well as marine and freshwater aquatic ecotoxicity impacts for the PFAAs. Common LCA-terms are explained in the Supporting Information, Table S1 and abbreviations used are listed in Section S1.

In LCIA, impact scores (ISs) for emission-related impacts are generally calculated as a product of emission (emitted mass per functional unit) and CF (impacts per emission unit). ${ }^{26}$ The functional unit is a quantitative representation of the function of the product under study, for example, $\mathrm{m}^{2} \times$ year for flooring. In line with this approach, we propose for a specific PFAS $x$ (the primary pollutant; a precursor to a PFAA or a PFAA) to obtain the IS as

$$
\begin{aligned}
& I \mathrm{~S}_{\mathrm{x}}=\sum_{i}\left(E_{i, x} \times \mathrm{CF}_{i, x, k}\right) \\
& \mathrm{CF}_{i, x, k}=f_{i, x, k} \times \mathrm{CF}_{i, k}
\end{aligned}
$$

where for each emitted precursor, the IS for aquatic ecotoxicity is the potentially affected fraction (PAF) of species integrated over exposed aquatic compartment volume and time, and the IS for human toxicity is the cumulative incidence risk in the exposed population. The fraction $\left(f_{i, x, k}\right)$ of the primary pollutant that is transformed into the PFAA $(k)$ in the emission compartment (set to $100 \%$, if the primary pollutant is a PFAA), is obtained in Step A: Transformation (Figure 1). The CFs are obtained in Step B: either by application of CFs as reported herein or by application of new CFs calculated with the PFAA-adapted model. The CFs for ecotoxicity impacts are in units of PAF $\mathrm{m}^{3} \mathrm{~d} / \mathrm{kg}_{\text {emitted }}$ and for human toxicity in units of disease cases $/ \mathrm{kg}_{\text {emitted }} . E_{i, x}$ is the emitted mass of the primary pollutant $x[\mathrm{~kg}$ ] to compartment $i$ (different amounts can be modeled to be emitted to several compartments simultaneously), derived in the LCI. Primary pollutants (other than PFAAs themselves) and stable intermediates will also contribute to the (eco)toxicity impacts. ${ }^{15}$ However, PFASs that are precursors to the PFAAs were not characterized for their untransformed structure as it was assessed to be of relatively low importance in the long term since transformation 
Table 1. Translation Table with Transformation Fractions to Derive Yields of Terminal Degradation Products from Primary Emissions of PFASs

\begin{tabular}{|c|c|c|c|}
\hline Primary pollutant (reported emission) & $\begin{array}{l}\text { Intermediate degradation } \\
\text { product }\end{array}$ & Terminal degradation product (PFAA) & 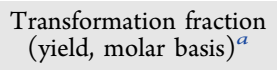 \\
\hline \multicolumn{4}{|l|}{ Nonpolymeric } \\
\hline PASF-based substances $\mathrm{C}_{n} \mathrm{~F}_{2 n+1}-\mathrm{SO}_{2}-\mathrm{R}$ & $\begin{array}{l}\text { plausible but not identified in the } \\
\text { present study }\end{array}$ & PFSAs (e.g., PFBS) $\mathrm{C}_{n} \mathrm{~F}_{2 n+1}-\mathrm{SO}_{3} \mathrm{H}$ & $60 \%$ \\
\hline $\begin{array}{l}\text { fluorotelomer-based substances } \\
\mathrm{C}_{n} \mathrm{~F}_{2 n+1}-\mathrm{C}_{2} \mathrm{H}_{4}-\mathrm{R}\end{array}$ & $\begin{array}{l}\text { plausible but not identified in the } \\
\text { present study }\end{array}$ & $\begin{array}{l}\text { PFCAs (e.g., PFHxA, PFOA) } \mathrm{C}_{n} \mathrm{~F}_{2 n+1}-\mathrm{COOH} \\
\quad \text { or } \mathrm{C}_{n-1} \mathrm{~F}_{2(n-1)+1}-\mathrm{COOH}\end{array}$ & $60 \%$ \\
\hline \multicolumn{4}{|l|}{ Polymeric } \\
\hline $\begin{array}{l}\text { PASF-based side-chain fluorinated polymers } \\
\mathrm{C}_{n} \mathrm{~F}_{2 n+1}-\mathrm{SO}_{2}-\mathrm{R}\end{array}$ & $\begin{array}{l}\text { non-polymeric PASF-based } \\
\text { substances }\end{array}$ & PFSAs (e.g., PFBS) $\mathrm{C}_{n} \mathrm{~F}_{2 n+1}-\mathrm{SO}_{3} \mathrm{H}$ & $0-60 \%^{b}$ \\
\hline $\begin{array}{l}\text { fluorotelomer-based side-chain fluorinated } \\
\text { polymers } \mathrm{C}_{n} \mathrm{~F}_{2 n+1}-\mathrm{C}_{2} \mathrm{H}_{4}-\mathrm{R}\end{array}$ & $\begin{array}{l}\text { non-polymeric fluorotelomer- } \\
\text { based substances }\end{array}$ & $\begin{array}{l}\text { PFCAs (e.g., PFHxA, PFOA) } \mathrm{C}_{n} \mathrm{~F}_{2 n+1}-\mathrm{COOH} \\
\quad \text { or } \mathrm{C}_{n-1} \mathrm{~F}_{2(n-1)+1}-\mathrm{COOH}\end{array}$ & $0-60 \%^{b}$ \\
\hline \multicolumn{4}{|c|}{ 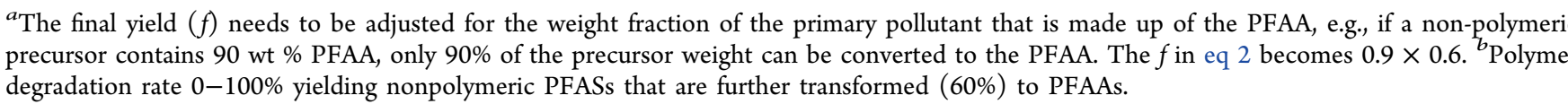 } \\
\hline
\end{tabular}

fractions used were high (see Section 3.1) and accumulation and exposure of the PFAAs will exceed that of their precursors. Characterization of primary pollutants and intermediate degradation products is however possible in this framework by calculation of the CF for the primary pollutant or intermediate itself and multiplication of that with its emission, in addition to the use of the CFs for the PFAAs as described in eq 2 .

Three representative terminal degradation products were chosen and CFs $\left(\mathrm{CF}_{i, k}\right.$ in eq 2) were calculated for them: two perfluoroalkyl carboxylic acids (PFCAs), namely PFOA and perfluorohexanoic acid (PFHxA), and a perfluoroalkanesulfonic acid (PFSA), namely perfluorobutanesulfonic acid (PFBS). PFBS and PFHxA were selected to give a good coverage for current LCAs including PFASs, as their perfluoroalkane sulfonyl fluoride (PASF)- and fluorotelomerbased precursor products are common on the market in applications such as surfactants and surface protectants. ${ }^{5,27,28}$ PFOA, which is being restricted and phased-out in Europe, ${ }^{13}$ was included as a reference substance. The impact characterization model can be used to calculate CFs for additional PFAAs.

2.2. Defining a Translation Table to Link Primary Emissions of PFASs with Terminal Degradation Products. A simplified translation key to derive the transformation fraction $f_{i, x, k}$ (eq 2) for impact characterization was defined based on literature data. ${ }^{29-33}$ To reduce complexity, any fate processes of the intermediate transformation products were decoupled and immediate formation of the PFAA was assumed despite the slow degradation of some intermediates. Irreversible removal by advective flows is not accounted for in this step as this is subsequently considered in the LCIA transport and fate model, which we used to characterize the PFAAs (see Section 2.3.1). Justification of the data selection is detailed in Section S3.

2.3. Proposing a Model for (Eco)Toxicity Impact Characterization Factors. 2.3.1. Model Selection and Adaptation. Aiming for consistency with existing consensusbuilding efforts to further the inclusion of (eco)toxicity impacts in $\mathrm{LCA}^{34,35}$ the USEtox model ${ }^{36}$ (version 2.1) was used as a starting point and adapted for integrating processes to describe PFAA-specific fate, exposure, and (eco)toxicity effects.
The USEtox multimedia fate model describes steady-state chemical mass-transfer including partitioning between media and phases, advection flows, and transformation and removal processes. The steady-state solution represents the long-term accumulation of a chemical that occurs when a (constant) release is allowed to continue over time (see, e.g., $\mathrm{ECHA}^{37}$ Guidance on environmental exposure assessment). Concentrations of PFASs may not reach steady-state in the real world due to dynamic use patterns, but USEtox steady-state concentrations provide a common basis for the evaluation of different chemicals under a set of standard conditions. The USEtox model comprises a multimedia fate (based on SimpleBox ${ }^{38}$ ), multipathway exposure and effect assessment module including nested indoor and urban air, and continental and global scale air, water and soil compartments (see Table 1 in Rosenbaum et al. ${ }^{36}$ and the USEtox model documentation $^{39}$ ). In USEtox, landscape parametrization allows modeling of different regions, mainly recommended for use as a sensitivity analysis of the default settings, and in this paper, USEtox' default settings were used.

In the USEtox CF calculation framework, CFs are calculated by multiplication of matrices containing fate factors (FFs), exposure factors (XFs), and effect factors (EFs); eq 3 (here with index $k$ indicating the PFAA, that is, the terminal degradation product unless the primary pollutant is a PFAA). For human toxicity, intake fractions (iFs), a summary metric of human exposure in relation to emissions, are calculated by matrix multiplication of FF and XF matrices. Within the framework proposed here, to arrive at an IS for the primary PFAS, the CFs applied in eq 2 are derived as

$$
\mathrm{CF}_{k}=\mathrm{FF}_{k} \times \mathrm{XF}_{k} \times \mathrm{EF}_{k}
$$

FFs describe chemical partitioning, dispersion, degradation, and transport in and between the various environmental compartments and are expressed in days [ $\mathrm{kg}_{\text {in compartment }} /$ $\left.\mathrm{kg}_{\text {emitted }} / \mathrm{d}\right]$, interpreted as the chemical residence time in a given compartment. For ecotoxicity, XFs are expressed as the mass fraction dissolved in water $\left[\mathrm{kg}_{\text {dissolved }} / \mathrm{kg}_{\text {in compartment }}\right]$; all of the substance present in the compartment which is not associated with suspended particles, dissolved organic carbon (DOC), or bioaccumulated in biota (bioaccumulation relevant for ecotoxicity is considered in the EF that represents longterm exposure conditions), and EFs describe the PAF of aquatic species integrated over exposed water volume [PAF 
$\mathrm{m}^{3} / \mathrm{kg}_{\text {dissolved }}$. The ecotoxicity $\mathrm{EF}$ is the change in PAF of species showing an increase in a given effect due to a change in dissolved contaminant concentration; it is the linearized slope of the concentration-response relationship up to the $\mathrm{HC}_{50}$ (hazardous concentration affecting $50 \%$ of the exposed species at their $\mathrm{EC}_{50}$, which is the species-specific effective concentration affecting $50 \%$ of the exposed population). ${ }^{40}$ For human toxicity, the iFs are expressed as intake via inhalation or ingestion per unit mass emitted $\left[\mathrm{kg}_{\text {intake }} / \mathrm{kg}_{\text {emitted }}\right]$, and EFs are expressed as cases per unit mass intake [cases/ $\left.\mathrm{kg}_{\text {intake }}\right]$. The human toxicity EF is the linearized slope of the dose-response relationship derived from a human lifetime $\mathrm{ED}_{50}$ (effective dose affecting $50 \%$ of exposed individuals for a defined end point). ${ }^{41}$ Further documentation on the USEtox model can be found elsewhere. ${ }^{36,39-41}$

To capture PFAA-specific properties, such as the combination of oleophobic and hydrophobic properties (which make the $K_{\mathrm{OW}}$ unsuitable as a basis for describing partitioning) and accumulation in the ocean, ${ }^{6}$ USEtox was adapted as described below and in Section S4 and Table S4. In summary, components of the original USEtox model that we specifically targeted for adaptation to PFASs were (i) partitioning in the environmental fate module (leading to changes in FFs and ecosystem XFs), (ii) plant bioaccumulation in the exposure module, and (iii) inclusion of marine ecotoxicity in the effect module. The model adapted for PFAAs is available as an electronic Supporting Information file. Data selection for the necessary substance data parameters for calculation of CFs is further outlined in Section 2.3.2 (and in Section S5).

In the environmental fate module, by analogy with previous fate modeling of PFASs, ${ }^{42}$ the $K_{\mathrm{OW}}$ dependence was circumvented by allowing for omission of $K_{\mathrm{OW}}$ by adjusting related algorithms describing the partitioning between the different media. PFAAs occur as anions under environmental conditions and although anions do not usually sorb strongly to organic matter, it has been shown that dissociated anions of PFAAs sorb to the organic carbon fraction of soils and sediments. ${ }^{43,44}$ Solids-water partitioning was adjusted accordingly to rely entirely on the organic carbon-water partitioning coefficient $\left(K_{\mathrm{OC}}\right)$. DOC-water partitioning was not adjusted in the model but $K_{\mathrm{DOC}}$ was obtained by back-calculation from $K_{\mathrm{OC}}$ (see Section S5.1). To allow for prediction of the air-water/ solids partitioning in the atmosphere, the aerosol-gas partition coefficient $\left(K_{\mathrm{QA}}\right)$ was used instead of $K_{\mathrm{OA}}$.

To avoid using $K_{\mathrm{OW}}$ for PFAAs in the exposure module, leaf concentration factors (LCFs), describing the air-plant transfer ratio of chemicals and in USEtox obtained as a function of $K_{\mathrm{OW}}$, were added as substance input parameters. This included separate LCFs for the transfer of chemicals from the gas phase in air and bound to air particles.

Marine ecotoxicity was introduced to the effect module, in accordance with the LC-Impact method for toxicity characterization, ${ }^{45}$ by addition of an EF for marine ecotoxicity and algorithms for calculation of the CF (marine ecotoxicity) with eq 3. To account for differences in continental versus global aquatic species richness, we used spatial distribution data of higher animal species from $\mathrm{IUCN}^{46}$ as proxy (12\% and $88 \%$ for the continental and global scale, respectively), acknowledging that other species should also be considered. This adjustment to species richness was implemented for both marine and freshwater ecotoxicity.

In USEtox, there is no groundwater compartment and chemicals removed from soil by leaching are considered to disappear. For very persistent and very mobile (vPvM) chemicals, such as PFAAs, this sink is substantial in relation to other flows from the soil compartments; for PFOA almost $50 \%$ of an emission would be discounted this way. To explore the importance of this sink, we introduced a modification giving an option to recirculate chemicals leached from the soil compartment (further detailed in Section S7). This soil leaching redirection was not used in the calculation of final CFs to avoid introduction of bias in comparisons with other vPvM substances.

2.3.2. Data Collection and Calculation of Characterization Factors. Substance data for the three focus PFAAs were collected by literature review focusing on peer-reviewed papers and reports from authorities, such as the European Chemicals Agency (ECHA). The data collection procedure for CF calculation outlined by Roos et al. ${ }^{18}$ was used as the starting point. To reduce uncertainty in the CFs, empirical data were given priority. The use of in silico methods to populate substance data parameters adds uncertainty to the CFs, ${ }^{47}$ and in the case of PFAAs this uncertainty may be high given that PFAAs are ionic, amphiphilic surfactants. In silico models available were listed (Section S6) to explore the possibility of their use in cases where experimental data were missing.

The final data set and justification of data selection is included in Table S5 and Sections S5.1-S5.3). In a first round, data were collected for PFOA, the most extensively studied of the three focus PFAAs, in a non-exhaustive manner. This was followed by sensitivity analysis varying the input parameters for $\mathrm{PFOA}\left(\mathrm{EC}_{50}\right.$ values were varied as their antilog values $) \pm 50 \%$ in clusters. The clustering was set up to capture covariation between parameters (see Table S10 for clusters and Section S8 for the results of the sensitivity analysis). For example, degradation in water, soil, and sediment was varied in one cluster as those parameters are closely connected. The sensitivity analysis identified the most influential parameters, here defined as those contributing to more than $5 \%$ to the total change in model output. The further data collection was focused on those most influential parameters and discontinued when the data had been evaluated by a relevant authority, when data allowed for calculation of a central estimate or when all available data had been collected (in addition to relevant authority websites, Scopus was the main search engine used). An uncertainty assessment was conducted by applying the minimum and maximum values per parameter in the same clusters as defined for the sensitivity analysis.

Due to high model sensitivity to data selected for the EFs, particular focus was placed on these parameters. EFs were calculated according to the USEtox 2.1 manual. ${ }^{48}$ (see Sections S5.1-5.3 for details). Human toxicity EFs were based on $\mathrm{ED}_{50}$ values calculated from repeated dose rodent studies. ${ }^{49-51}$ However, epidemiological studies indicate that PFOA effect levels are orders of magnitude lower than what animal studies have been able to show (PFHxA and PFBS have not been included in epidemiological studies to the same extent). ${ }^{49,52}$ Therefore, in an additional uncertainty assessment, epidemiological data were tested to derive roughly extrapolated EFs, based on an assumption of similar toxic potencies at equal internal concentrations ${ }^{53}$ (Section S5.4). Ecotoxicity EFs were based on data from recent reviews, ${ }^{18,50}$ and to further expand the ecotoxicity data sets, to reduce uncertainty, ${ }^{54}$ recently developed extrapolation factors to arrive at chronic $\mathrm{EC}_{50}$ values were used. ${ }^{55}$ 
CFs were calculated for the focus substances using the PFAAs model, based on and adapted from USEtox, and data as described above (and in greater detail in Section S5). These CFs allow for the calculation of ISs for these PFAAs and their precursors, the primary pollutants. To assess the relative magnitude of the CFs, their rank in relation to CFs calculated with data in the USEtox organic substances database 2.01 [built 10 July 2017, $n=3077$ ] and USEtox inorganic substances database 2.0 [built 25 August 2015, $n=27$ ], were investigated. To be able to compare the CFs for marine ecotoxicity, the USEtox databases were extended with marine ecotoxicity, by applying freshwater ecotoxicity data as proxy for marine ecotoxicity data.

CFs cannot be validated per se, but FFs can be evaluated by back-calculation of predicted concentrations and comparison of those against measurements. For this article, this kind of model evaluation was made by comparison of predicted concentrations based on estimated emissions ${ }^{32}$ and environmental measurements ${ }^{56-60}$ as reported in Section S7.

2.4. Illustrative LCA Case Study on PFASs in Medical Textiles. An illustrative case of a comparative LCA was constructed, comparing two types of surgical drapes: one impregnated with PFASs (C-6 fluorinated acrylic copolymer, i.e., a side-chain fluorinated polymer) for protection from textile permeable liquids, and one non-impregnated drape that instead had an impermeable plastic film inner-layer. The surgical drapes were compared in an LCA from cradle-to-gate (final product at the factory) with the functional unit of "provision of liquid repellency for protection of one $\mathrm{m}^{2}$ for a single surgical procedure". We acknowledge that the usage, liquid barrier performance/protection levels, as well as the use phase comfort will be different between the two surgical drapes, but find the case appropriate for illustrative purposes. ISs were calculated by application of eq 1 . Since the case was only intended to illustrate the framework, the potential impacts studied were limited to global warming and (eco)toxicity. The latter meant characterizing PFASs with the framework for PFASs proposed here, that is, with CFs calculated with the PFAA model based on and adapted from USEtox, and with the official USEtox 2.1 factors (with the marine ecotoxicity extension) for all other chemicals emitted, whereas global warming was characterized with factors for the 100 years' time horizon from the IPPC. ${ }^{61}$ Global warming was selected as the additional impact category to (eco)toxicity as it is the most commonly used LCIA indicator ${ }^{62}$ and is therefore illustrative of key perspectives beyond (eco)toxicity in an LCIA framework. The bill of materials (BOM) and LCI (including emissions of PFASs) for the case study are detailed in the Section S12.

\section{RESULTS AND DISCUSSION}

\subsection{Translation Table to Link Primary Emissions with} PFAA Terminal Degradation Products. Transformation fractions were derived for application to any LCI of PFASs as primary pollutants (Table 1, further detailed in Section S3). For the PASF-based products, the primary pollutant $\left(\mathrm{C}_{n} \mathrm{~F}_{2 \mathrm{n}+1^{-}}\right.$ $\left.\mathrm{SO}_{2}-\mathrm{R}\right)$ was assigned to yield the PFSA $\left(\mathrm{C}_{n} \mathrm{~F}_{2 n+1}-\mathrm{SO}_{3} \mathrm{H}\right)$, while for any fluorotelomer-based substance $\left(\mathrm{C}_{n} \mathrm{~F}_{2 n+1}-\mathrm{C}_{2} \mathrm{H}_{4}-\mathrm{R}\right)$, PFCAs with uneven perfluorinated carbons were assigned as degradation products, that is, $\mathrm{C}_{n} \mathrm{~F}_{2 n+1}-\mathrm{COOH}$ or $\mathrm{C}_{n-1} \mathrm{~F}_{2(n-1)+1^{-}}$ $\mathrm{COOH}$.

PFCAs with uneven perfluorinated carbons (e.g., PFOA with seven perfluorinated carbons) and PFSAs with even perfluori- nated carbons (e.g., PFBS with four perfluorinated carbons) were used as proxies for all PFAAs generated by degradation of the primary pollutant. The overestimation of the occurrence of certain PFASs, such as PFOA and PFHxA (degradation products of, e.g., 8:2 and 6:2 FTOH), and exclusion of other PFASs, such as PFHpA and PFPeA (other degradation products of, for example, 8:2 and 6:2 FTOH) is currently justifiable because of missing (eco)toxicity data for many PFASs. ${ }^{5}$ Using the more extensively studied substances as proxies for less studied substances is desirable, as many emissions of PFASs would otherwise have been associated with data gaps and thus been left uncharacterized, leading to potential underestimations of impacts from product systems containing PFASs.

The transformation fraction for the non-polymeric PFASs $(60 \%)$ is based on PFAA yields observed by Liu et al., ${ }^{33}$ in line with an evaluation by $\mathrm{ECHA}^{31}$ estimating $80 \%$ PFOA yield. As yields will differ between precursors and environmental media it was not considered relevant to set an exact value, but to find an approximate value relevant for the long time scales modeled in this framework. Application of an 60\% transformation fraction also to the PASF-based substances may lead to an overestimation of the transformation to PFSAs as PASF-based substances can also degrade to PFCAs in the environment. $^{63-65}$ Transformation of PASF-based substances to PFCAs was assumed not to occur in this simplified scheme. Polymer degradation was not possible to quantify ${ }^{50,66}$ and a range of $0-100 \%$ was included (see Section S3). Emission compartments are assigned to the chemicals where they are expected to be created, for example, an emission of a side-chain fluorinated polymer to land, generating an $\mathrm{FTOH}$ emission to air that degrades to PFCA, generates a PFCA emission to air (see, e.g., $\mathrm{Li}$ et al. $^{67}$ ). Thus, if the degradation product is generated in a compartment $(j)$ downstream from the primary emission compartment, in eq 2 the CF would need to be for $j$ and the $f$ would describe the overall transformation. When the compartment where the chemical is generated is not known it is assigned to the primary emission compartment, that is, where the primary pollutant was emitted. A future more complex scheme could include a fate module to allow for better predictions of emission compartments and transformation yields, and include transformation of PASF-based substances to the corresponding PFCAs and PFSAs and consideration of their combined impacts.

3.2. Human Toxicity and Aquatic Ecotoxicity Impact Characterization for PFAAs. CFs and partial model results are summarized in the Table S14.

3.2.1. Fate Factors and Model Evaluation. Although the predicted concentrations in the relatively small freshwater and drinking water compartments are higher, consistent with observations (Figure S2), the majority of the mass $\left[\mathrm{kg}_{\text {in }}\right.$ compartment $\left./\left(\mathrm{kg}_{\text {emitted }} / \mathrm{d}\right)\right]$ of the three PFAAs, namely PFOA, PFHxA, and PFBS, was predicted to reside almost completely in the open ocean at steady-state, independent of the emission compartment (see Figures S3-S5 for FFs). The global ocean becomes the main storage reservoir for PFAAs because watersoluble PFAAs runoff from land or are atmospherically deposited there, and once they arrive in the ocean they stay for a long time. ${ }^{6}$ The model's estimation of fate is thus in line with the expected fate of PFAAs and observations. ${ }^{6}$ Predicted continental compartment average concentrations were higher than median measured concentrations for water and air compartments (see Figure S2). Predicted global average 


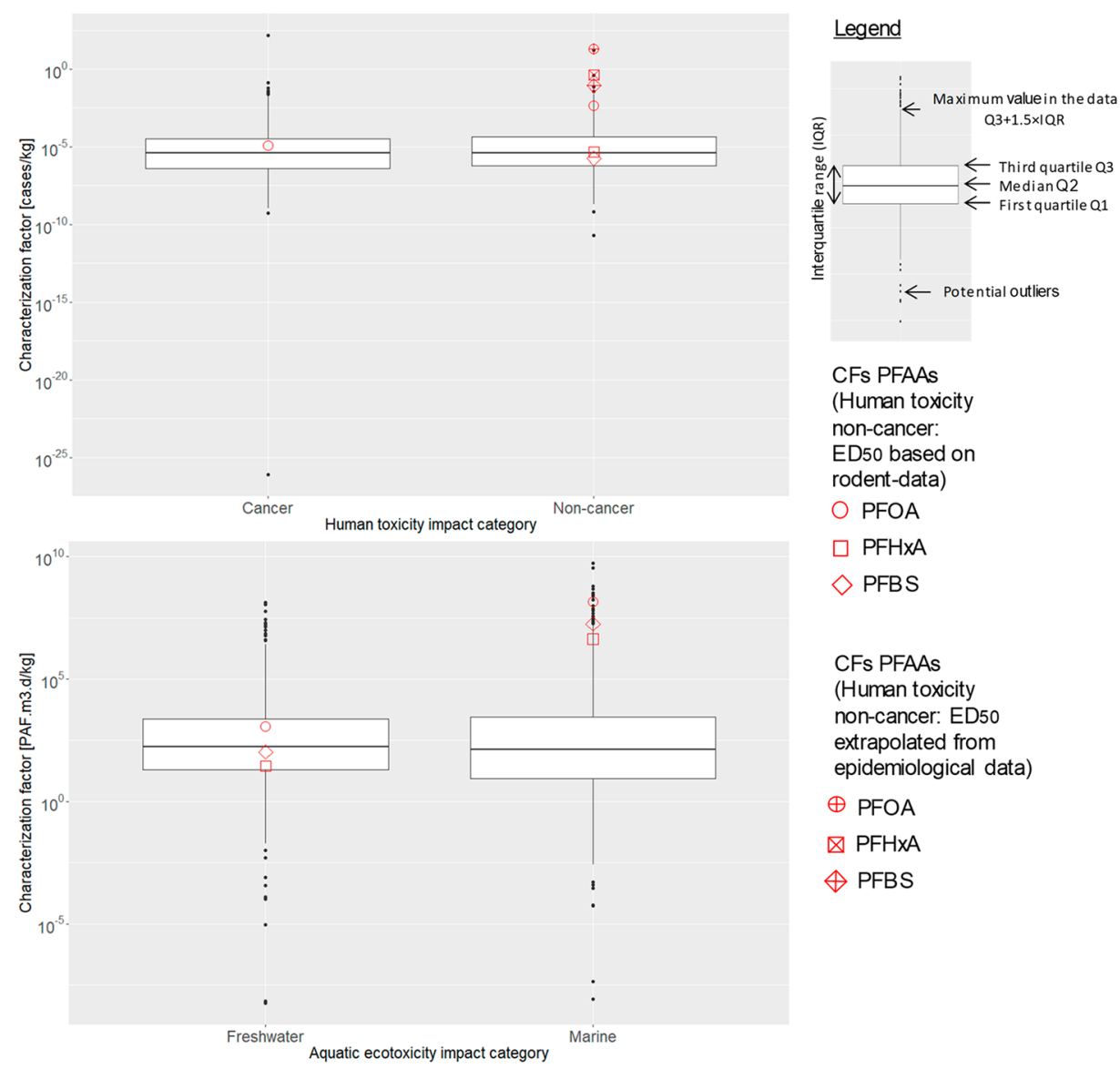

Figure 2. Characterization factors (CFs, shown in $\log _{10}$ scale) for freshwater emissions for the three PFAAs (highlighted values, human toxicity CFs for non-cancer effects differentiated for rodent- and extrapolated epidemiological data based effect factors) and their rank in relation boxplots of all CFs as obtained from existing USEtox databases (Organics and metal ions, with marine extension. Human toxicity cancer $(n=612)$ and noncancer $(n=441)$ in the upper panel and aquatic ecotoxicity $(n=2523)$ in the lower panel. For the cancer effects non-carcinogenic chemicals are not displayed).

concentrations were close to the measured median for air, lower than the 25th percentile for freshwater (and drinking water), and higher than the maximum for marine water. Several uncertainties can contribute to these deviations, for example, the aggregation of global emissions to one continent; however, it is consistent with the reasoning that the PFAAs have not yet reached steady-state in the environment. Despite the appropriateness of the model's overprediction of marine concentrations of PFAAs, it may be worthwhile considering disaggregating that compartment into a surface and a deepwater subcompartment. It has recently been shown that, for example, PFOS residence time in the ocean surface water, most relevant for ecotoxicity impacts, could be as short as a few years, ${ }^{8}$ compared to the very long residence time modeled here (more than 6000 years in the global ocean).

Exploration of the importance of the leaching from soil as an environmental sink, showed that when the emissions were directed to soils, the recirculation of chemicals into the freshwater compartment increased FFs for freshwater by almost a factor of 4 for all three PFAAs. For emissions to continental air, freshwater FFs increased by almost a factor of 2. This shows that with the long-term time perspectives modeled here this sink does reduce the CFs for vPvM substances, but these increases in FFs increase the CFs by less than an order of magnitude (up to a factor of 2) and are thus relatively unimportant compared to other factors discussed in this paper.

FFs of the three PFAAs ranked high in comparison to substances in the USEtox database (Figure S6) for soil and aquatic compartments. For the open ocean the FFs were predicted to be more than 5 orders of magnitude higher than the median FF.

3.2.2. Exposure and Intake Fractions. For all emission compartments except indoor air and continental seawater, human exposure via drinking water and meat consumption were predicted to be the main exposure pathways for PFOA (Figure S7). This is a deviation from, for example, the Swedish situation, where Vestergren et al. ${ }^{68}$ found that for PFOA dietary exposure originated from a wider range of foods including cereals and dairy products. PFHxA intake was predicted to be mainly from drinking water and dairy products and PFBS intake mainly from drinking water and below ground produce (SI Figures S7-S9). Bioaccumulation factor (BAF) and biotransfer factor (BTF) uncertainty likely contribute to a large extent to differences in intake pathways between the substances. Ecotoxicity XFs (mass fraction of a chemical that is bioavailable) were close to 1 for PFOA, PFHxA and PFBS, that is, they were predicted to occur almost completely in the dissolved form.

3.2.3. Effect Factors. EFs for PFOA, PFHxA, and PFBS human toxicity and ecotoxicity, in relation to EFs calculated 
with USEtox databases, are shown in the Figures S10 and S11. The non-cancer PFOA EF based on rodent data was higher than the 75th percentile, whereas the PFHxA and PFBS EFs were at and below the 25 th percentile. The non-cancer EFs based on roughly extrapolated human epidemiological data on the other hand, were 4 orders of magnitude higher than the median EF. The cancer-EFs for PFOA, the only carcinogenic substance of the three, was below the median EF. For ecotoxicity PFOA ranked highest of the three PFAAs, close to the median ecotoxicity EF, followed by PFBS and PFHxA, both below the 25th percentile. EFs were identical for freshwater and marine ecotoxicity due to the merged data sets for freshwater and marine species. The spread in ecotoxicity EFs across the three PFAAs could reflect data availability rather than an actual difference in ecotoxicity.

3.2.4. Characterization Factor Results. The PFAA CFs were compared to CFs obtained with the USEtox organic and inorganic substances databases (Figure 2). For human toxicity impacts, the PFOA non-cancer CF (based on rodent-data EFs) was above the 75th percentile, but PFHxA and PFBS CFs were at or below median. CFs based EFs from roughly extrapolated epidemiological data were above the 95th percentile for all three PFAAs. Of these three substances, only PFOA is assessed as carcinogenic, ranking in the mid segment of cancer CFs. Human intake of these PFAAs, with low bioaccumulation factors in fish (Section S5), comes mainly from other sources than the global ocean (Figures S7-S9), and thus the large environmental accumulation in the ocean is not as important for the CF for human toxicity. For marine aquatic ecotoxicity, all three PFAAs ranked high in the comparison with CFs for 2523 substances with a wide range of physiochemical properties, while they ranked in the lower segments for freshwater ecotoxicity. This result was due to high exposures (mainly due to high FFs), as none of these substances is very ecotoxic according to current knowledge, as reflected in their relatively low EFs (Figure S11). Rankings were similar for the CFs for emissions to soil and air (not showed here). CFs were calculated for the focus substances and are listed in the Supporting Information together with FFs, XFs, and EFs for all compartments (in the PFAA adapted model; Section S11).

Roos et al. ${ }^{18}$ calculated human toxicity CFs for the three PFAAs and those deviated by at most 1 order of magnitude from CFs presented here (based on rodent-data EFs), due to data choices for the EFs and differences in fate and exposure modeling. However, CFs herein, based on EFs roughly extrapolated from epidemiological data, were all higher by orders of magnitude than those presented by Roos et al. ${ }^{18} \mathrm{~A}$ comparison between CFs for freshwater ecotoxicity by Roos et al. ${ }^{18}$ and the CFs calculated herein showed that except for emissions to seawater they were within the same order of magnitude. Despite the similar freshwater ecotoxicity CFs calculated by Roos et al., ${ }^{18}$ the global ecotoxicity impacts would be considerably underestimated by their use because of the exclusion of the marine aquatic ecotoxicity impact category (a result of the use of an unadapted USEtox model).

The sensitivity analysis for PFOA (parameter values increased/decreased by $50 \%$ in clusters) showed that the most influential parameters were those that were the basis for calculating the $\mathrm{EF}$ (i.e., $\mathrm{ED}_{50}$ for human toxicity and $\mathrm{HC}_{50}$ for ecotoxicity impacts), which contributed to a change in the CFs for human toxicity and ecotoxicity with a factor of 2 (see Section S8). Degradation rates for PFOA in water, soil and sediment were shown to be of high importance; affecting the marine ecotoxicity CFs almost by a factor of 2 . The only other parameters contributing to more than $5 \%$ of change in the $\mathrm{CF}$ were $K_{\mathrm{OC}}, \mathrm{BAF}_{\text {meat } / \text { milk, }}$ and $\mathrm{BAF}_{\text {root/leaf }} / \mathrm{LCF}_{\text {air }}$. Model sensitivity will vary between substance types due to the nonlinearity between the substance data used as input and the model output. ${ }^{69}$ The PFAAs studied here are however expected to impart similar model sensitivities.

The uncertainty analysis for PFOA, PFHxA, and PFBS showed that the large span in input data for $K_{\mathrm{OC}}$ and degradation rates had a large effect on the resulting CFs as they changed with more than an order of magnitude compared to the best-estimate (Section S9). When the fate and exposure parameters were varied individually, the deviations between the CFs obtained with minimum/maximum values and the best estimate were at most approximately 2 orders of magnitude. The combined uncertainty for the fate and exposure parameters, varying all parameters at the same time, was also within 2 orders of magnitude (see calculation example in Section S9). The parameters that had the largest effect on the $\mathrm{CF}$ varied between substances, due to differences in data availability. Some uncertainties are completely unaccounted for (namely air-plant LCFs for all three PFAAs, soil-root BAF for PFHxA, soil-leaf BAF for PFBS, BTF meat $_{\text {for }}$ PFHxA and $\mathrm{BTF}_{\text {milk }}$, and $\mathrm{BAF}_{\text {fish }}$ for PFHxA and PFBS) due to the low data availability, which did not allow for quantifying ranges. Based on these results, we estimate a parameter uncertainty for the fate and exposure parameters of approximately 2 orders of magnitude, probably lower. For effect data, uncertainty ranges cannot be derived in the same way as for other parameters as all reliable data are used to derive EFs (variability is unaccounted for here due to lack of data on distributions). The limits to data and current knowledge, for example, if the relevant sensitive end points and species have been tested, are important contributors to uncertainty. ${ }^{54,70}$ This was illustrated by the large difference between human health non-cancer EFs, and in extension, CFs, when based on rodent-data compared to rough extrapolations from epidemiological data (Figure 2). In addition to parameter uncertainty, there are also 2 and 3 orders of magnitude model uncertainty for ecotoxicity and human toxicity CFs, respectively. ${ }^{36}$ The combined uncertainty, that is, minimum 4 orders of magnitude, is a large uncertainty but can be justified for comparative purposes of CFs that vary over a range of more than 13 and 19 orders of magnitude across substances for human toxicity and ecotoxicity impacts, respectively.

3.3. Case Study Illustrating the Framework in Practice. We have proposed an (eco)toxicity LCIA framework for PFASs, that guides the LCA-analyst from the inventory stage to the final characterization of potential impacts from a product or service. This framework allows for characterization of potential impacts of fluorotelomer- and PASF-based products as well as direct use of PFAAs, thus covering the vast majority of PFAS-containing products on the market. ${ }^{27}$ Application of this framework makes it possible to quantitatively include potential PFAS-related toxicity impacts in LCA studies.

To apply the framework the LCA-analyst needs to go through two main steps, as illustrated in Figure 1, and the detailed case study description (Section S12). The starting point is an inventory of primary emissions of PFASs; $E$ in eq 1 . In the case study, no emissions of PFASs were included in the available LCI data sets despite their coverage of PFAS industrial processes (which would not be an uncommon 
situation), and emissions of primary PFASs pollutants (here as a C6 copolymer and its impurity 6:2 FTOH) had to be added to the LCI by application of emission factors (6\% and $30 \%$ to water, ${ }^{37}$ for the manufacture and finishing steps, respectively, further reduced by sewage treatment) to the mass of polymer used $(0.01 \mathrm{~kg})$ per functional unit. For volatile residues, $0.2 \%^{71}$ was set to be lost to outdoor air. The LCI was created by use of the guidance provided in Section S3. The transformation and LCIA was conducted in two steps (Figure 1):

Step A. Assign each primary pollutant a terminal degradation product and transformation fraction $\left(f_{i, x, k}\right.$ in eq 2 ) by use of the translation table (Table 1 ). In the case study the terminal degradation product of the C-6 fluorotelomer based copolymer $(1 \mathrm{H}, 1 \mathrm{H}, 2 \mathrm{H}, 2 \mathrm{H}$-Perfluorooctyl acrylate; $\left.\mathrm{C}_{6} \mathrm{~F}_{13} \mathrm{C}_{2} \mathrm{H}_{4} \mathrm{OCOC}_{2} \mathrm{H}_{2}\right)$ and 6:2 FTOH $\left(\mathrm{C}_{6} \mathrm{~F}_{13} \mathrm{C}_{2} \mathrm{H}_{4} \mathrm{OH}\right)$ was PFHxA. The transformation fractions $\left(f_{i, x, k}\right)$ were set to $23 \%$ $(0.5 \times 0.75 \times 0.6 ; 50 \%$ polymer degradation, $75 \%$ PFHxA by weight in the polymer and $60 \%$ yield from subsequent nonpolymer degradation) for polymer degradation, and 52\% (60\% conversion from 6:2 FTOH to PFHxA and 86\% PFHxA by weight in the molecule) for the non-polymeric fluorotelomer based substances. Uncertainty in degradation yields was explored in emission scenarios (Section S12.3).

Step $B$. Calculate $\mathrm{CF}_{i, x, k}$ for the primary pollutant, with $f_{i, x, k}$ from Step A and CFs for PFAAs as presented in this paper, or with the use of additional CFs calculated with the PFAAsadapted LCIA model. Calculate ISs by multiplication of $\mathrm{CF}_{i, x, k}$ with $E_{i, x}$ (eq 1 ). In the case study the CFs for PFHxA were used. The ISs calculated based on PFAS emissions were then added to the total IS per (eco)toxicity impact category and functional unit.

The DWR-impregnated drape could not be differentiated from the plastic-coated drape (taking parameter and model uncertainty into account), when conventional data on human toxicity was used (rodent-data) (Figure S12). It is worth noting that DWR-drape related chemical emissions other than PFASs are underestimated in this simplified case study as it is primarily intended to illustrate how the (eco)toxicity characterization framework for PFASs can be applied. The sensitivity of the results to PFAS transformation fractions was explored with three scenarios (Section S12.3): basic (50\% polymer degradation/60\% PFAA yield from non-polymer degradation), low $(0 \% / 30 \%)$ and high $(100 \% / 90 \%)$. In the basic scenario, with rodent-data based EFs as basis for the CFs, the total IS for the DWR impregnated drape was 6.9 and 3500 PAF $\mathrm{m}^{3} \mathrm{~d}$ for freshwater and marine ecotoxicity respectively and $1.6 \times 10^{-9}$ and $2.1 \times 10^{-9}$ cases for human toxicity cancer and non-cancer effects, respectively. Less than $2 \%$ of the (eco)toxicity ISs was due PFHxA contributions. However, with EFs based on epidemiological data as basis for CFs, the high potential toxicity breaks through the results, and the DWRdrape was modeled to have more than 800 times the impact of the plastic-coated drape in the non-cancer impact category. The PFHxA contribution was almost 100\%. Comparing potential impacts between the low and basic scenarios, it becomes evident that the inclusion of polymer degradation is imperative for the results where polymeric PFAS are used and emitted. Recent modeling efforts support fluorotelomer polymer half-lives of decades, ${ }^{72}$ making the $50 \%$ polymer degradation applied in the case study basic scenario a cautious scenario, as almost all polymer would degrade over 100 years with a 10 year half-life.
In other types of product life cycles, with high emissions of PFASs per functional unit, all types of fluorotelomer based and PASF-based PFASs will dominate the IS for marine aquatic ecotoxicity due to the high transformation fractions and the high CFs of their terminal degradation products. The high CFs for human toxicity non-cancer effects, when based on EFs that were roughly extrapolated from epidemiological data, also show that high potential human health impacts could be associated with PFAS-containing products. These are potential impacts that would have gone unrecognized without the use of the framework presented here.

3.4. Limitations and Recommendations for the Application of the LCIA-Framework for PFASs. The (eco)toxicity LCIA-framework for PFASs presented herein address key issues identified for assessment of PFASs. ${ }^{5}$ Despite those efforts to allow for sound and robust inclusion of emissions of PFASs in LCIA, this framework is still constrained by limitations centered around parameter and model uncertainty. Two major causes of uncertainty deserve to be highlighted: (i) degradation rates and pathways that generate degradation products, and (ii) uncertainty in the EFs.

Degradation rates and pathways that generate terminal degradation products, in particular for side-chain fluorinated polymers, are highly uncertain, reflected in the wide range of degradation scenarios suggested herein for polymers. The LCA-analyst is recommended to investigate the outcome of both extremes of the suggested range of $0-100 \%$ polymer degradation. Better degradation scenarios for polymers will reduce uncertainty but may be difficult to obtain due to the long half-lives, which are difficult to cover experimentally. A more advanced model for estimation of precursor degradation can be fit into this framework, reducing uncertainty but increasing complexity and thus risking reduced utility. Another factor of high relevance for PFASs, ${ }^{69}$ is the case that landfills are not included in the USEtox model. Thus, in the framework presented here, landfill emissions are not calculated by use of the transformation fractions (Table 1), but are treated as part of the technosphere and handled in the LCI.

For human health non-cancer effects, EFs and the CFs derived from them, are highly uncertain. The limited mechanistic understanding of the (eco)toxicity of PFASs creates difficulties in data selection. The large difference between CFs based on rodent-data EFs and CFs based EFs roughly extrapolated from epidemiological data (Figure 2), and the implication of this in case study results (Figure S12), show how uncertain EFs can have drastic effects on LCA results. Furthermore, critical effects for PFOA are being re-evaluated, ${ }^{52}$ and while newly proposed limit values (tolerable weekly intake (TWI) $8 \mathrm{ng} / \mathrm{kg} \mathrm{bw}$, for the sum of four PFAAs) are in close proximity to those proposed in 2018 (TWI $6 \mathrm{ng} / \mathrm{kg}$ bw for PFOA $),{ }^{49}$ used to calculate human-data based EFs here, it is apparent that knowledge about PFAS effects is continuously evolving. The ecotoxicological EFs, based on averages across several species, were assessed as more robust. The risk of future lowered thresholds is particularly problematic for extremely persistent chemicals, such as the PFAAs, as contamination will be poorly reversible. ${ }^{7,73-76}$

Due to the aggregation of emission flows over the life cycle, and the use of a standardized evaluative environment (the PFAA model based on and adapted from USEtox), the potential impacts modeled by use of this framework are generic. This is in line with the scope of LCA: identification of potential problem shifting and optimization of its environ- 
mental performance. By adjusting landscape parameters in USEtox, regionalized scenarios can be set up. Nevertheless, the framework proposed is not for assessing acceptability of PFASrelated risks to certain groups of the population or certain ecosystems.

The framework suggested herein is an attempt to carefully use the information about PFASs available to date, with specific focus on the effects of these substances' persistence and incorporate that information into an existing LCIA concept and model. As such, this framework makes it possible, for the first time, to comprehensively include emissions of PFASs in LCA. Previous studies have had to either leave out PFASs, despite their relevance to the study objectives, limit the modeling of the cause-effect chain to emissions and exposures, leaving out (eco)toxicity effects or rely on CFs not adapted to properties of PFASs. $^{20-25}$ As shown in Figure 2, and illustrated with the case study (Figure S12), such inclusion can drastically change the outcome of the LCA due to the high potential for (eco)toxicity impacts of the terminal degradation products, the PFAAs.

\section{ASSOCIATED CONTENT}

\section{SI Supporting Information}

The Supporting Information is available free of charge at https://pubs.acs.org/doi/10.1021/acs.est.9b07774.

Background information and further details for the Methods and Results/Discussion sections (PDF)

The PFAA adapted LCIA model and CFs for PFOA, PFHxA, and PFBS (ZIP)

\section{AUTHOR INFORMATION}

\section{Corresponding Author}

Hanna Holmquist - Division of Environmental Systems Analysis, Chalmers University of Technology, SE-412 96 Gothenburg, Sweden; 이이.org/0000-0002-6213-0754; Phone: +46 3177263 18; Email: hannaholmquist82@ gmail.com

\section{Authors}

Peter Fantke - Quantitative Sustainability Assessment, Department of Technology, Management and Economics, Technical University of Denmark, 2800, Kgs, Lyngby, Denmark; 이이.org/0000-0001-7148-6982

Ian T. Cousins - Department of Environmental Science, Stockholm University, SE-106 91 Stockholm, Sweden; (1) orcid.org/0000-0002-7035-8660

Mikołaj Owsianiak - Quantitative Sustainability Assessment, Department of Technology, Management and Economics, Technical University of Denmark, 2800, Kgs, Lyngby, Denmark; 이이.org/0000-0002-6834-6249

Ioannis Liagkouridis - Department of Environmental Science, Stockholm University, SE-106 91 Stockholm, Sweden; (1) orcid.org/0000-0003-1204-5495

Gregory M. Peters - Division of Environmental Systems Analysis, Chalmers University of Technology, SE-412 96

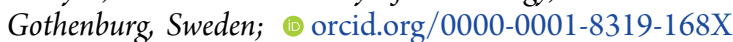

Complete contact information is available at: https://pubs.acs.org/10.1021/acs.est.9b07774

\section{Notes}

The authors declare no competing financial interest.

\section{ACKNOWLEDGMENTS}

This research was funded by the Swedish Research Council for Environment, Agricultural Sciences and Spatial Planning (FORMAS) under grant agreement no. 2012-2148 (Project SUPFES) and SUPFES Health, a daughter project jointly funded by Region Stockholm and Stockholm University.

\section{REFERENCES}

(1) Baumann, H.; Tillman, A.-M. The Hitch Hiker's Guide to LCA. An orientation in life cycle assessment methodology and application, 1:7 ed.; Studentlitteratur: Malmö, Sweden, 2004.

(2) OECD Portal on Per and Poly Fluorinated Chemicals. http:// www.oecd.org/chemicalsafety/portal-perfluorinated-chemicals/ (accessed 2018/8/31).

(3) Kissa, E. Fluorinated Surfactants and Repellents, 2nd ed.; Marcel Dekker Inc.: New York Basel, 2001; Vol. 97, p 615.

(4) Barton, C. A.; Botelho, M. A.; Kaiser, M. A. Solid vapor pressure and enthalpy of sublimation for perfluorooctanoic acid. J. Chem. Eng. Data 2008, 53 (4), 939-941.

(5) Wang, Z.; DeWitt, J. C.; Higgins, C. P.; Cousins, I. T. A NeverEnding Story of Per- and Polyfluoroalkyl Substances (PFASs)? Environ. Sci. Technol. 2017, 51 (5), 2508-2518.

(6) Prevedouros, K.; Cousins, I. T.; Buck, R. C.; Korzeniowski, S. H. Sources, fate and transport of perfluorocarboxylates. Environ. Sci. Technol. 2006, 40 (1), 32-44.

(7) Cousins, I. T.; Vestergren, R.; Wang, Z.; Scheringer, M.; McLachlan, M. S. The precautionary principle and chemicals management: The example of perfluoroalkyl acids in groundwater. Environ. Int. 2016, 94, 331-340.

(8) Zhang, X. M.; Zhang, Y. X.; Dassuncao, C.; Lohmann, R.; Sunderland, E. M. North Atlantic Deep Water formation inhibits high Arctic contamination by continental perfluorooctane sulfonate discharges. Global Biogeochem. Cycles 2017, 31 (8), 1332-1343.

(9) Blum, A.; Balan, S. A.; Scheringer, M.; Trier, X.; Goldenman, G.; Cousins, I. T.; Diamond, M.; Fletcher, T.; Higgins, C.; Lindeman, A. E.; Peaslee, G.; de Voogt, P.; Wang, Z.; Weber, R. The Madrid Statement on Poly- and Perfluoroalkyl Substances (PFASs). Environ. Health Perspect. 2015, 123 (5), A107-11.

(10) Scheringer, M.; Trier, X.; Cousins, I. T.; de Voogt, P.; Fletcher, T.; Wang, Z.; Webster, T. F. Helsingor statement on poly- and perfluorinated alkyl substances (PFASs). Chemosphere 2014, 114, 337-9.

(11) Stockholm Convention The new POPs under the Stockholm Convention http://chm.pops.int/TheConvention/ThePOPs/ TheNewPOPs/tabid/2511/Default.aspx (accessed 2014/11/18).

(12) Vierke, L.; Staude, C.; Biegel-Engler, A.; Drost, W.; Schulte, C. Perfluorooctanoic acid (PFOA) - main concerns and regulatory developments in Europe from an environmental point of view. Environ. Sci. Eur. 2012, 24 (16), 1-11.

(13) European Commission, Commission Regulation (EU). 2017/ 1000 of 13 June 2017 amendingAnnex XVII to Regulation (EC) No 1907/2006 of the European Parliament and of the Council concerning the Registration, Evaluation, Authorisation and Restriction of Chemicals (REACH) as regards perfluorooctanoic acid (PFOA), its salts and PFOA-related substances (Text with EEA relevance.), 2017; Vol. C, 3907.

(14) Jones, P. D.; Hu, W.; De Coen, W.; Newsted, J. L.; Giesy, J. P. Binding of perfluorinated fatty acids to serum proteins. Environ. Toxicol. Chem. 2003, 22 (11), 2639-49.

(15) van Zelm, R.; Huijbregts, M. A.; van de Meent, D. Transformation products in the life cycle impact assessment of chemicals. Environ. Sci. Technol. 2010, 44 (3), 1004-9.

(16) Huijbregts, M. A. J.; Steinmann, Z. J. N.; Elshout, P. M. F.; Stam, G.; Verones, F.; Vieira, M. D. M.; Hollander, A.; Zijp, M.; van Zelm, R. ReCiPe 2016 v1.1 A harmonized life cycle impact assessment method at midpoint and endpoint level Report I: Characterization RIVM Report 2016-0104a; National Institute for Public Health and the Environment, 2017. 
(17) Oers, L. v. CML-IA database, characterisation and normalisation factors for midpoint impact category indicators, 2015; http:// www.cml.leiden.edu/software/data-cmlia.html (accessed 2018/9/24).

(18) Roos, S.; Holmquist, H.; Jonsson, C.; Arvidsson, R. USEtox characterisation factors for textile chemicals based on a transparent data source selection strategy. Int. J. Life Cycle Assess. 2018, 23 (4), 890-903.

(19) Frischknecht, R.; Knöpfel, S. B. Swiss Eco-Factors 2013 according to the Ecological Scarcity Method, 2013; http://www.bafu. admin.ch/uw-1330-e (accessed 2017/9/18).

(20) Life Cycle Assessment of a GORE Branded Waterproof, Windproof and Breathable Jacket. Summary Report; W. L. Gore \& Associates GmbH, 2013; https://www.gore-tex.com/sites/default/files/assets/ Gore_LCA_summary_report.pdf (accessed 2020/4/14).

(21) Life Cycle Assessment of DWR treatments on waterproof, windproof and breathable jacket. Summary report.; W. L. Gore \& Associates GmbH: 2015; http://www.gore-tex.com/cms-images/ 211/672/Gore-DWR-LCA-summary-report\%20151215.pdf (accessed 2015/12/15).

(22) Fierro, J.; Martínez, C. Environmental Life Cycle Assessment Studies of the Alternative DWOR Chemicals; Mitigation of Environmental Impact Caused by DWOR Textile Finishing Chemicals Studying Their Nontoxic Alternatives, 2018; https:// www.midwor-life.eu/download/2566/2018-10-08.

(23) Zhu, J. X.; Kang, S. G.; Xie, Y. J.; Zhang, F. S. Preliminary environmental impact assessment of PFOS waste treatment in a labscale batch subcritical water decomposition operation. J. Mater. Cycles Waste Manage. 2013, 15 (4), 489-502.

(24) Emery, I.; Kempisty, D.; Fain, B.; Mbonimpa, E. Evaluation of treatment options for well water contaminated with perfluorinated alkyl substances using life cycle assessment. Int. J. Life Cycle Assess. 2019, 24 (1), 117-128.

(25) Meng, J.; Lu, Y.; Wang, T.; Wang, P.; Giesy, J. P.; Sweetman, A. J.; Li, Q. Life cycle analysis of perfluorooctanoic acid (PFOA) and its salts in China. Environ. Sci. Pollut. Res. 2017, 24 (12), 11254-11264. (26) Finnveden, G.; Hauschild, M. Z.; Ekvall, T.; Guinee, J.; Heijungs, R.; Hellweg, S.; Koehler, A.; Pennington, D.; Suh, S. Recent developments in Life Cycle Assessment. J. Environ. Manage. 2009, 91 (1), $1-21$.

(27) Buck, R. C.; Franklin, J.; Berger, U.; Conder, J. M.; Cousins, I. T.; de Voogt, P.; Jensen, A. A.; Kannan, K.; Mabury, S. A.; van Leeuwen, S. P. Perfluoroalkyl and polyfluoroalkyl substances in the environment: terminology, classification, and origins. Integr. Environ. Assess. Manage. 2011, 7 (4), 513-41.

(28) OECD. PFCS: Outcome of the 2009 Survey Survey on the Production, Use and Release of PFOS, PFAS, PFOA PFCA, Their Related Substances and Products/Mixtures Containing These Substances Series on Risk Management No.24. ; JT03294854; Organisation for Economic Co-operation and Development (OECD): Paris, 2011; http://www. oecd.org/officialdocuments/publicdisplaydocumentpdf/?cote=env/ $\mathrm{jm} / \mathrm{mono}(2011) 1 \&$ doclanguage $=$ en $($ accessed 2020/4/14).

(29) Butt, C. M.; Muir, D. C.; Mabury, S. A. Biotransformation pathways of fluorotelomer-based polyfluoroalkyl substances: a review. Environ. Toxicol. Chem. 2014, 33 (2), 243-67.

(30) Liu, J.; Mejia Avendano, S. Microbial degradation of polyfluoroalkyl chemicals in the environment: a review. Environ. Int. 2013, 61, 98-114.

(31) ECHA. ANNEX XV Restriction Report Proposal for a Restriction Substance Name: Perfluorooctanoic acid (PFOA), PFOA salts and PFOA-related substances; 17 October 2014; https:/ / echa.europa.eu/documents/10162/e9cddee6-3164-473db590-8fcf9caa50e7 (accessed 2020/3/13).

(32) Wang, Z.; Cousins, I. T.; Scheringer, M.; Buck, R. C.; Hungerbuhler, K. Global emission inventories for C4-C14 perfluoroalkyl carboxylic acid (PFCA) homologues from 1951 to 2030, Part I: production and emissions from quantifiable sources. Environ. Int. 2014, 70, 62-75.

(33) Liu, J.; Wang, N.; Szostek, B.; Buck, R. C.; Panciroli, P. K.; Folsom, P. W.; Sulecki, L. M.; Bellin, C. A. 6-2 Fluorotelomer alcohol aerobic biodegradation in soil and mixed bacterial culture. Chemosphere 2010, 78 (4), 437-444.

(34) Westh, T. B.; Hauschild, M. Z.; Birkved, M.; Jorgensen, M. S.; Rosenbaum, R. K.; Fantke, P. The USEtox story: a survey of model developer visions and user requirements. Int. J. Life Cycle Assess. 2015, 20 (2), 299-310.

(35) Fantke, P.; Aurisano, N.; Bare, J.; Backhaus, T.; Bulle, C.; Chapman, P. M.; De Zwart, D.; Dwyer, R.; Ernstoff, A.; Golsteijn, L.; Holmquist, H.; Jolliet, O.; McKone, T. E.; Owsianiak, M.; Peijnenburg, W.; Posthuma, L.; Roos, S.; Saouter, E.; Schowanek, D.; van Straalen, N. M.; Vijver, M. G.; Hauschild, M. Toward harmonizing ecotoxicity characterization in life cycle impact assessment. Environ. Toxicol. Chem. 2018, 37 (12), 2955-2971.

(36) Rosenbaum, R. K.; Bachmann, T. M.; Gold, L. S.; Huijbregts, M. A.; Jolliet, O.; Juraske, R.; Koehler, A.; Larsen, H. F.; MacLeod, M.; Margni, M. USEtox - the UNEP-SETAC toxicity model: recommended characterisation factors for human toxicity and freshwater ecotoxicity in life cycle impact assessment. Int. J. Life Cycle Assess. 2008, 13 (7), 532-546.

(37) ECHA Guidance on information requirements and Chemical Safety Assessment. Chapter R.16: Environmental exposure assessment, 2016; ISBN: 978-92-9247-775-2, https://echa.europa.eu/ documents/10162/13632/information_requirements_r16_en.pdf/ b9f0f406-ff5f-4315-908e-e5f83115d6af.

(38) Brandes, L. J.; den Hollander, H.; van de Meent, D. SimpleBox 2.0: a nested multimedia fate model for evaluating the environmental fate of chemicals; National Institute of Public Health and the Environment: Bilthoven, The Netherlands, 1996; p 155.

(39) Fantke, P.; Bijster, M.; Guignard, C.; Hauschild, M.; Huijbregts, M.; Jolliet, O.; Kounina, A.; Magaud, V.; Margni, M.; McKone, T.; Posthuma, L.; Rosenbaum, R. K.; Meent, D. v. d.; Zelm, R. v. USEtox ${ }^{\circledR} 2.0$ Documentation (Version 1); ISBN: 978-87-998335-04; 2017; p 208.

(40) Henderson, A. D.; Hauschild, M. Z.; van de Meent, D.; Huijbregts, M. A. J.; Larsen, H. F.; Margni, M.; McKone, T. E.; Payet, J.; Rosenbaum, R. K.; Jolliet, O. USEtox fate and ecotoxicity factors for comparative assessment of toxic emissions in life cycle analysis: sensitivity to key chemical properties. Int. J. Life Cycle Assess. 2011, 16 (8), 701-709.

(41) Rosenbaum, R. K.; Huijbregts, M. A. J.; Henderson, A. D.; Margni, M.; McKone, T. E.; van de Meent, D.; Hauschild, M. Z.; Shaked, S.; Li, D. S.; Gold, L. S.; Jolliet, O. USEtox human exposure and toxicity factors for comparative assessment of toxic emissions in life cycle analysis: sensitivity to key chemical properties. Int. J. Life Cycle Assess. 2011, 16 (8), 710-727.

(42) Armitage, J.; Cousins, I. T.; Buck, R. C.; Prevedouros, K.; Russell, M. H.; MacLeod, M.; Korzeniowski, S. H. Modeling globalscale fate and transport of perfluorooctanoate emitted from direct sources. Environ. Sci. Technol. 2006, 40 (22), 6969-75.

(43) Guelfo, J. L.; Higgins, C. P. Subsurface transport potential of perfluoroalkyl acids at aqueous film-forming foam (AFFF)-impacted sites. Environ. Sci. Technol. 2013, 47 (9), 4164-71.

(44) Higgins, C. P.; Luthy, R. G. Sorption of perfluorinated surfactants on sediments. Environ. Sci. Technol. 2006, 40 (23), 72516.

(45) Fantke, P.; Owsianiak, M. Toxicity. In LC-IMPACT Version 1.0. A Spatially Differentiated Life Cycle Impact Assessment Approach; Verones, F.; Huijbregts, M. A. J.; B. Azevedo, L.; Chaudhary, A.; Cosme, N.; Baan, L. d.; Fantke, P.; Hauschild, M.; Henderson, A. D.; Jolliet, O.; Mutel, C. L.; Owsianiak, M.; Pfister, S.; Preiss, P.; Roy, P.O.; Scherer, L.; Steinmann, Z.; Zelm, R. v.; Dingenen, R. V.; Goethem, T. v.; Vieira, M.; Hellweg, S., Eds.; LC-Impact: 2019; https://lc-impact.eu/; pp 118-134.

(46) IUCN (International Union for Conservation of Nature and Natural Resources) Spatial Data. https://www.iucnredlist.org/ resources/spatial-data-download (accessed 2018/10/03).

(47) Holmquist, H.; Lexen, J.; Rahmberg, M.; Sahlin, U.; Palm, J. G.; Rydberg, T. The potential to use QSAR to populate ecotoxicity 
characterisation factors for simplified LCIA and chemical prioritisation. Int. J. Life Cycle Assess. 2018, 23 (11), 2208-2216.

(48) USEtox ${ }^{\circledR} 2.0$ User Manual (Version 2); Huijbregts, M.; Margni, M.; Hauschild, M.; Jolliet, O.; McKone, T.; Rosenbaum, R.; Meent, D. v. d.; Fantke, P., Eds.; 2015; http://www.usetox.org/ (accessed 2016/5/27).

(49) EFSA Panel Contaminants Food Chain; Knutsen, H. K.; Alexander, J.; Barregard, L.; Bignami, M.; Bruschweiler, B.; Ceccatelli, S.; Cottrill, B.; Dinovi, M.; Edler, L.; Grasl-Kraupp, B.; Hogstrand, C.; Hoogenboom, L.; Nebbia, C. S.; Oswald, I. P.; Petersen, A.; Rose, M.; Roudot, A. C.; Vleminckx, C.; Vollmer, G.; Wallace, H.; Bodin, L.; Cravedi, J. P.; Halldorsson, T. I.; Haug, L. S.; Johansson, N.; van Loveren, H.; Gergelova, P.; Mackay, K.; Levorato, S.; van Manen, M.; Schwerdtle, A. T. Risk to human health related to the presence of perfluorooctane sulfonic acid and perfluorooctanoic acid in food. EFSA J. 2018, 16 (12), 5194.

(50) Holmquist, H.; Schellenberger, S.; van der Veen, I.; Peters, G. M.; Leonards, P. E.; Cousins, I. T. Properties, performance and associated hazards of state-of-the-art durable water repellent (DWR) chemistry for textile finishing. Environ. Int. 2016, 91, 251-64.

(51) ECHA, Committee for Risk Assessment (RAC) Committee for Socio-economic Analysis (SEAC) Background document to the Opinion on the Annex $\mathrm{XV}$ dossier proposing restrictions on Perfluorooctanoic acid (PFOA), PFOA salts and PFOA-related substances ECHA/RAC/RES-O-0000006229-70-02/F ECHA/ SEAC/[reference code to be added after the adoption of the SEAC opinion]. 2015.

(52) EFSA CONTAM Panel (EFSA Panel on Contaminants in the Food Chain); Schrenk, D.; Bignami, M.; Bodin, L.; Chipman, J. K.; del Mazo, J.; Grasl-Kraupp, B.; Hogstrand, C.; Hoogenboom, L. R.; Leblanc, J.-C.; Nebbia, C. S.; Nielsen, E.; Ntzani, E.; Petersen, A.; Sand, S.; Vleminckx, C.; Wallace, H.; Barregård, L.; Cravedi, J.-P.; Haldorsson, T. I.; Haug, L. S.; Johansson, N.; Knutsen, H. K.; Rose, M.; Roudot, A.-C.; van Loveren, H.; Vollmer, G.; Mackay, K.; Riolo, F.; Schwerdtle, T., Scientific opinion on the risk for human health related to the presence of perfluoroalkyl substances in food.. EFSA J. 2020, In review.

(53) Gomis, M. I.; Vestergren, R.; Borg, D.; Cousins, I. T. Comparing the toxic potency in vivo of long-chain perfluoroalkyl acids and fluorinated alternatives. Environ. Int. 2018, 113, 1-9.

(54) Douziech, M.; Oldenkamp, R.; van Zelm, R.; King, H.; Hendriks, A. J.; Ficheux, A. S.; Huijbregts, M. A. J. Confronting variability with uncertainty in the ecotoxicological impact assessment of down-the-drain products. Environ. Int. 2019, 126, 37-45.

(55) Aurisano, N.; Albizzati, P. F.; Hauschild, M.; Fantke, P. Extrapolation Factors for Characterizing Freshwater Ecotoxicity Effects. Environ. Toxicol. Chem. 2019, 38 (11), 2568-2582.

(56) Zareitalabad, P.; Siemens, J.; Hamer, M.; Amelung, W. Perfluorooctanoic acid (PFOA) and perfluorooctanesulfonic acid (PFOS) in surface waters, sediments, soils and wastewater - A review on concentrations and distribution coefficients. Chemosphere 2013, 91 (6), 725-32.

(57) Jian, J. M.; Guo, Y.; Zeng, L.; Liang-Ying, L.; Lu, X.; Wang, F.; Zeng, E. Y. Global distribution of perfluorochemicals (PFCs) in potential human exposure source-A review. Environ. Int. 2017, 108, $51-62$.

(58) Wong, F.; Shoeib, M.; Katsoyiannis, A.; Eckhardt, S.; Stohl, A.; Bohlin-Nizzetto, P.; Li, H.; Fellin, P.; Su, Y. S.; Hung, H. Assessing temporal trends and source regions of per- and polyfluoroalkyl substances (PFASs) in air under the Arctic Monitoring and Assessment Programme (AMAP). Atmos. Environ. 2018, 172, 65-73. (59) Johansson, J. H.; Salter, M. E.; Acosta Navarro, J. C.; Leck, C.; Nilsson, E. D.; Cousins, I. T. Global transport of perfluoroalkyl acids via sea spray aerosol. Environ. Sci. Process Impacts 2019, 21 (4), 635649.

(60) Originator: Norwegian Institute for Air Research, N., Environmental Chemistry Department. Station Zeppelin Mountain (Ny Ålesund) and Andoya, Matrix: air+aerosol. In European
Monitoring and Evaluation Programme (EMEP), 2006-2018: EBAS, http://ebas.nilu.no/ (accessed 2018/10/8).

(61) IPCC Climate Change 2013: The Physical Science Basis. In Contribution of Working Group I to the Fifth Assessment Report of the Intergovernmental Panel on Climate Change; Stocker, T. F., Qin, D.; Plattner, G.-K.; Tignor, M.; Allen, S.K.; Boschung, J.; Nauels, A.; Xia, Y.; Bex, V.; Midgley, P. M., Eds.; 110705799X; Cambridge, United Kingdom and New York, NY, USA, 2013; p 1535, https://www.ipcc. $\mathrm{ch} / \mathrm{report} / \mathrm{ar} 5 / \mathrm{wg} 1 /$ (accessed 2020/4/14).

(62) Sandin, G.; Peters, G. M. Environmental impact of textile reuse and recycling - A review. J. Cleaner Prod. 2018, 184, 353-365.

(63) Martin, J. W.; Ellis, D. A.; Mabury, S. A.; Hurley, M. D.; Wallington, T. J. Atmospheric chemistry of perfluoroalkanesulfonamides: kinetic and product studies of the $\mathrm{OH}$ radical and $\mathrm{Cl}$ atom initiated oxidation of N-ethyl perfluorobutanesulfonamide. Environ. Sci. Technol. 2006, 40 (3), 864-72.

(64) Schenker, U.; Scheringer, M.; MacLeod, M.; Martin, J. W.; Cousins, I. T.; Hungerbuhler, K. Contribution of volatile precursor substances to the flux of perfluorooctanoate to the Arctic. Environ. Sci. Technol. 2008, 42 (10), 3710-6.

(65) D’Eon J, C.; Hurley, M. D.; Wallington, T. J.; Mabury, S. A. Atmospheric chemistry of $\mathrm{N}$-methyl perfluorobutane sulfonamidoethanol, C4F9SO2N(CH3) $\mathrm{CH} 2 \mathrm{CH} 2 \mathrm{OH}$ : kinetics and mechanism of reaction with OH. Environ. Sci. Technol. 2006, 40 (6), 1862-8.

(66) Russell, M. H.; Berti, W. R.; Szostek, B.; Buck, R. C. Investigation of the biodegradation potential of a fluoroacrylate polymer product in aerobic soils. Environ. Sci. Technol. 2008, 42 (3), $800-7$.

(67) Li, L.; Liu, J.; Hu, J.; Wania, F. Degradation of fluorotelomerbased polymers contributes to the global occurrence of fluorotelomer alcohol and perfluoroalkyl carboxylates: a combined dynamic substance flow and environmental fate modeling analysis. Environ. Sci. Technol. 2017, 51 (8), 4461-4470.

(68) Vestergren, R.; Berger, U.; Glynn, A.; Cousins, I. T. Dietary exposure to perfluoroalkyl acids for the Swedish population in 1999, 2005 and 2010. Environ. Int. 2012, 49, 120-7.

(69) Wender, B.; Prado, V.; Fantke, P.; Ravikumar, D.; Seager, T. P. Sensitivity-based research prioritization through stochastic characterization modeling. Int. J. Life Cycle Assess. 2018, 23 (2), 324-332.

(70) Saouter, E.; Aschberger, K.; Fantke, P.; Hauschild, M.; Bopp, S.; Kienzler, A.; Paini, A.; Pant, R.; Secchi, M.; Sala, S. Improving Substance Information in Usetox ${ }^{\circledR}$, Part 1: Discussion on Data and Approaches For Estimating Freshwater Ecotoxicity Effect Factors. Environ. Toxicol. Chem. 2017, 36 (12), 3450-3462.

(71) Hischier, R.; Hellweg, S.; Capello, C.; Primas, A. Establishing life cycle inventories of chemicals based on differing data availability (9 pp). Int. J. Life Cycle Assess. 2005, 10 (1), 59-67.

(72) Washington, J. W.; Rankin, K.; Libelo, E. L.; Lynch, D. G.; Cyterski, M. Determining global background soil PFAS loads and the fluorotelomer-based polymer degradation rates that can account for these loads. Sci. Total Environ. 2019, 651, 2444-2449.

(73) Steffen, W.; Richardson, K.; Rockstrom, J.; Cornell, S. E.; Fetzer, I.; Bennett, E. M.; Biggs, R.; Carpenter, S. R.; de Vries, W.; de Wit, C. A.; Folke, C.; Gerten, D.; Heinke, J.; Mace, G. M.; Persson, L. M.; Ramanathan, V.; Reyers, B.; Sorlin, S. Sustainability. Planetary boundaries: guiding human development on a changing planet. Science 2015, 347 (6223), 736-746.

(74) MacLeod, M.; Breitholtz, M.; Cousins, I. T.; de Wit, C. A.; Persson, L. M.; Ruden, C.; McLachlan, M. S. Identifying Chemicals That Are Planetary Boundary Threats. Environ. Sci. Technol. 2014, 48 (19), 11057-11063.

(75) Persson, L. M.; Breitholtz, M.; Cousins, I. T.; de Wit, C. A.; MacLeod, M.; McLachlan, M. S. Confronting unknown planetary boundary threats from chemical pollution. Environ. Sci. Technol. 2013, 47 (22), 12619-22.

(76) Cousins, I. T.; Ng, C. A.; Wang, Z.; Scheringer, M. Why is high persistence alone a major cause of concern? Environ. Sci. Process Impacts 2019, 21 (5), 781-792. 